\title{
Clinical forensic radiology in strangulation victims: forensic expertise based on magnetic resonance imaging (MRI) findings
}

\author{
Kathrin Yen • Peter Vock • Andreas Christe • \\ Eva Scheurer • Thomas Plattner • Corinna Schön • \\ Emin Aghayev • Christian Jackowski • Verena Beutler • \\ Michael J. Thali $\cdot$ Richard Dirnhofer
}

Received: 28 December 2005 / Accepted: 21 July 2006 / Published online: 6 January 2007

(C) Springer-Verlag 2007

\begin{abstract}
Based on only one objective and several subjective signs, the forensic classification of strangulation incidents concerning their life-threatening quality can be problematic. Reflecting that it is almost impossible to detect internal injuries of the neck with the standard forensic external examination, we examined 14 persons who have survived manual and ligature strangulation or forearm choke holds using MRI technique (1.5-T scanner). Two clinical radiologists evaluated the neck findings independently. The danger to life was evaluated based on the "classical" external findings alone and in addition to the radiological data. We observed hemorrhaging in the subcutaneous fatty tissue of the neck in ten cases. Other frequent findings were hemorrhages of the neck and larynx
\end{abstract}

K. Yen $(\bowtie)$

Medical University of Graz, Center of Theoretical-Clinical

Medicine, Forensic, Pathologic and Anatomic Imaging,

Harrachgasse 21,

8010 Graz, Austria

e-mail: kathrin.yen@meduni-graz.at

K. Yen • E. Scheurer • T. Plattner $\cdot$ C. Schön $\cdot$ E. Aghayev $\cdot$

C. Jackowski $\cdot$ M. J. Thali $\cdot$ R. Dirnhofer

Institute of Forensic Medicine, University of Bern,

IRM-Buehlstrasse 20,

3012 Bern, Switzerland

V. Beutler

Department of Clinical Research,

Magnetic Resonance Spectroscopy and Methodology,

University of Bern,

Bern, Switzerland

P. Vock · A. Christe

Institute of Diagnostic Radiology, Inselspital Bern,

Freiburgstr. 20,

3012 Bern, Switzerland muscles, the lymph nodes, the pharynx, and larynx soft tissues. Based on the classical forensic strangulation findings with MRI, eight of the cases were declared as life-endangering incidents, four of them without the presence of petechial hemorrhage but with further signs of impaired brain function due to hypoxia. The accuracy of future forensic classification of the danger to life will probably be increased when it is based not only on one objective and several subjective signs but also on the evidence of inner neck injuries. However, further prospective studies including larger cohorts are necessary to clarify the value of the inner neck injuries in the forensic classification of surviving strangulation victims.

Keywords MRI $\cdot$ Strangulation $\cdot$ Neck injuries $\cdot$ Petechiae . Mortal danger $\cdot$ Clinical forensic radiology

\section{Introduction}

The examination of survivors of manual or ligature strangulation is frequently performed in routine forensic practice. The forensic assessment of these incidents is mainly based on an external examination of the body. The questioning of the victim and, if available, the perpetrator or other witnesses is also taken into account when providing forensic expertise. In all survived strangulation cases, the main issue with regard to the judicial verdict is whether the incident led to a lifethreatening situation or not. There is only one objective sign with which to determine this fact, namely petechial hemorrhages of the conjunctivae, eyelids, oral mucosa, and the facial skin. All other signs indicating severe strangulation are supposed to reflect cerebral hypoxia; 
however, they all have the inconvenience of being subjective and based on the reports of the involved persons (e.g., loss of consciousness, loss of urine or feces, psychiatric signs of central hypoxia such as the experience of hallucinatory phenomena) [1-6]. When it comes to examining living persons after strangulation, external examination of all body parts including the search for petechial hemorrhages is performed. Further clinical examinations such as CT or laryngoscopy are performed only if there is clinical suspicion of laryngeal injury that could require medical treatment. All internal findings, which are well-known from autopsy (e.g., muscle and subcutaneous hemorrhage, laryngeal injuries, lymph node and salivary gland hemorrhage) escape today's forensic examination of survived strangulation cases.

Because of the lack of objective signs reflecting severe strangulation, it becomes obvious that visualizing internal strangulation-related neck injuries could increase the accuracy of forensic expertise in these cases, especially when taking into account the internal findings for the interpretation of the life-threatening quality of an act.

In the Virtopsy context ( http://www.virtopsy.com) [7-11], fatal strangulation cases have been investigated using postmortem multislice computed tomography and magnetic resonance imaging (MRI); the results of these examinations that were performed in comparison with the autopsy findings were recently reported [12], along with the results of one surviving manual strangulation and one near-hanging case. The imaging results observed in the postmortem cases served as the basis for consecutive MRI examinations in survived strangulation cases, which were admitted to the forensic institute for expertise. The goal of this study was to evaluate the internal neck injuries in the living and to explore whether they could serve as a basis for a forensic interpretation of the life-threatening quality in future casework.

\section{Materials and methods}

\section{Cases}

We examined 14 persons who survived strangulation incidents (10 manual strangulations, 2 ligature strangulations, and 2 choke holds; 2 men, 12 women, mean age 32.6 years, range 19-45 years). The cases represented a continuous sample of persons who were admitted to the Institute of Forensic Pathology by the local justice departments for forensic examination and reconstruction of the sequence of events. Informed consent was obtained from all study participants.

Case 1: Nineteen-year-old woman. Manual strangulation by a serial offender. Loss of consciousness and loss of urine were reported by the victim. Numerous petechial hemorrhages were found in the eyelids and the oral mucosa upon external examination. The MRI scan was performed $16 \mathrm{~h}$ after the incident.

Case 2: Forty-year-old woman. Manual strangulation by her husband while lying in bed causing dizziness and a "blackout." No petechiae, localized pain on palpation in the larynx region. MRI scan $15.5 \mathrm{~h}$ after the incident (Fig. 4).

Case 3: Forty-five-year-old woman. Manual strangulation by husband while lying on the floor. Loss of consciousness. The victim reported hallucinatory phenomena shortly before losing consciousness. Petechial hemorrhages were found in the eyelids and facial skin during the forensic examination. MRI scan $3 \mathrm{~h}$ after the incident (Fig. 2).

Case 4: Twenty-one-year-old woman. Ligature strangulation with a belt while lying on a bed, with the perpetrator sitting on the victim. Impaired vision ("seeing black void") while being strangled was reported. Upon external examination, petechiae were present in the right upper and lower eyelid and the facial skin. MRI scan $13.5 \mathrm{~h}$ after the act (see Figs. 1 and 2).

Case 5: Eighteen-year-old man suffering a forearm choke hold by another man. He reported impaired vision (seeing black void) during the incident. Numerous petechial hemorrhages in the facial skin and painful palpation of the neck were found at the external examination. MRI scan $38 \mathrm{~h}$ after strangulation (Fig. 3).

Case 6: Twenty-nine-year-old woman. Manual strangulation causing impaired vision (seeing black void). No petechial hemorrhages upon external examination. MRI scan $42 \mathrm{~h}$ after the incident.

Case 7: Twenty-year-old woman after manual strangulation. No loss of consciousness but impaired vision (seeing black void) was reported. No petechiae. MRI scan $53.5 \mathrm{~h}$ after the incident.

Case 8: Forty-five-year-old woman who was submitted to the forensic institute after sexual assault (without strangulation). During the examination, the victim reported ligature strangulation with a belt 10 days before the actual incident. Persistent pain on pressure on the left side of the neck. No externally visible findings on the neck and no petechial hemorrhages were found during external examination. The MRI examination was performed approximately $300 \mathrm{~h}$ after the strangulation incident (Fig. 3).

Case 9: Thirty-five-year-old woman. Manual strangulation by a man using only the right hand, 

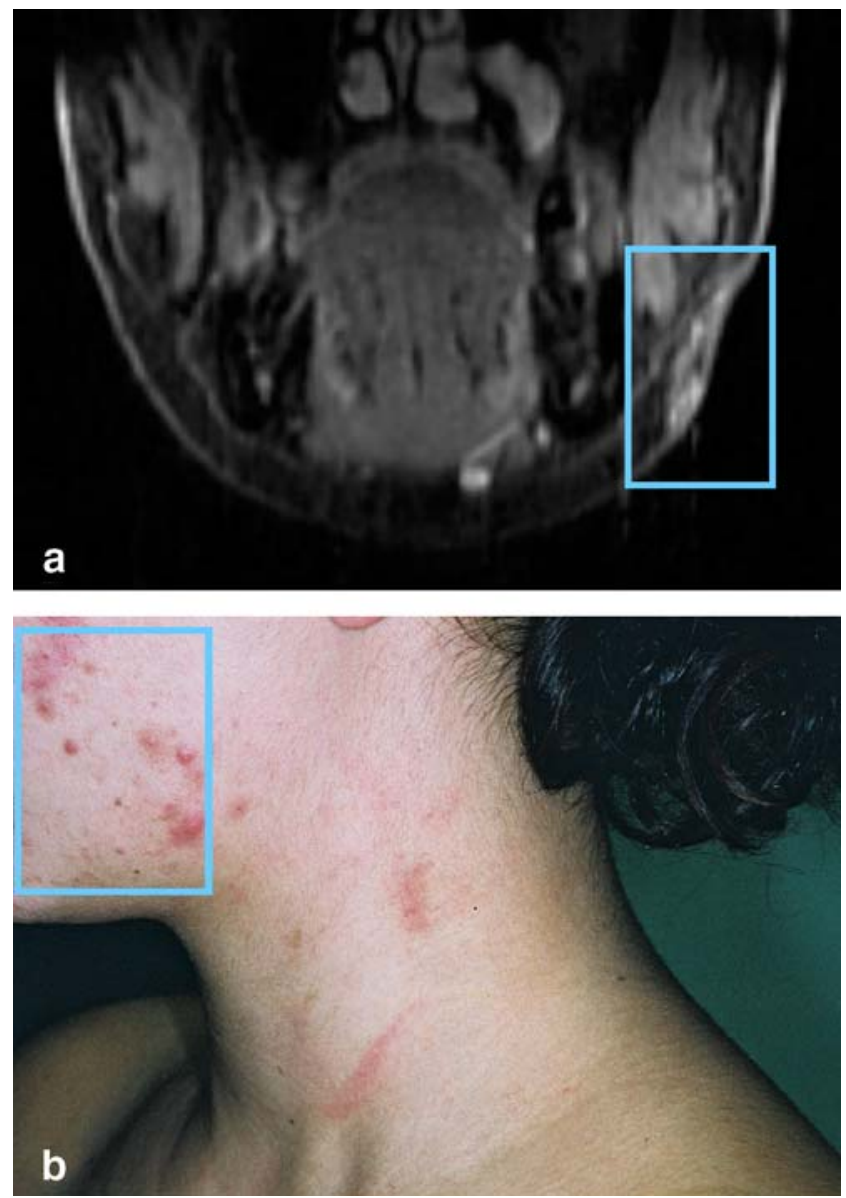

Fig. 1 Case 4, ligature strangulation. a Coronal STIR-weighted MR image (TR 3000, TE 14, TI 150) depicting a hyperintense subcutaneous region above the mandible on the left side (frame). The finding corresponded to hemorrhage of the subcutaneous fatty tissue. Apart from its intracutaneous part, the hemorrhagic lesion could not be explained by acne due to its extent and depth, which was not corresponding with acne alterations. b Corresponding photograph of the patient showing alterations due to acne but no traumatic bruises or abrasions in the injured region

causing impaired vision (seeing black void). Pain on pressure in the laryngeal region. No petechiae. MRI scan $19 \mathrm{~h}$ after the act (Fig. 4).

Case 10: Thirty-six-year-old woman, manual strangulation. The victim reported loss of consciousness. No petechial hemorrhages were present. Pain on pressure on the neck. MRI scan $20.5 \mathrm{~h}$ after the incident.

Case 11: Forty-five-year-old woman. Ligature strangulation by an unknown male with a shoelace. The victim suffered impaired vision (seeing black void), no loss of consciousness. No petechial hemorrhages. MRI scan $43 \mathrm{~h}$ after the act.

Case 12: Thirty-one-year-old woman. Manual strangulation with only the right hand. The victim

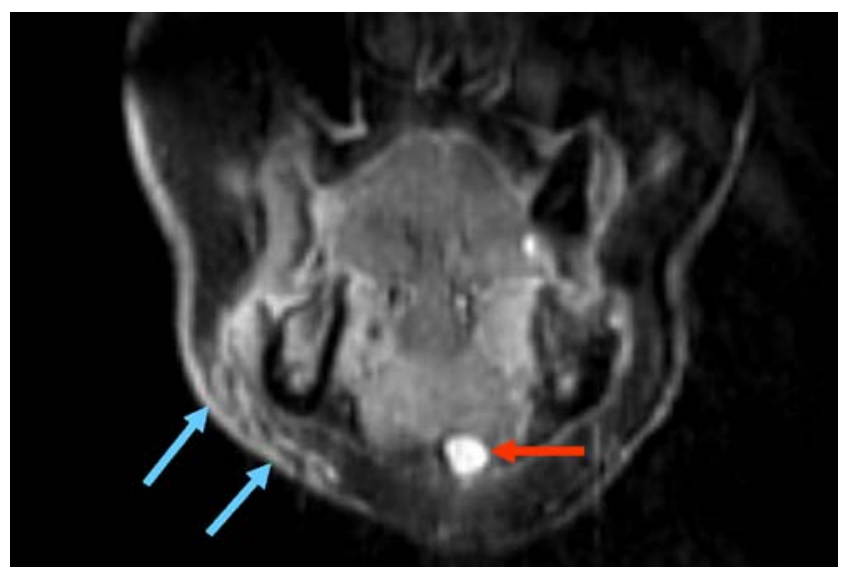

a

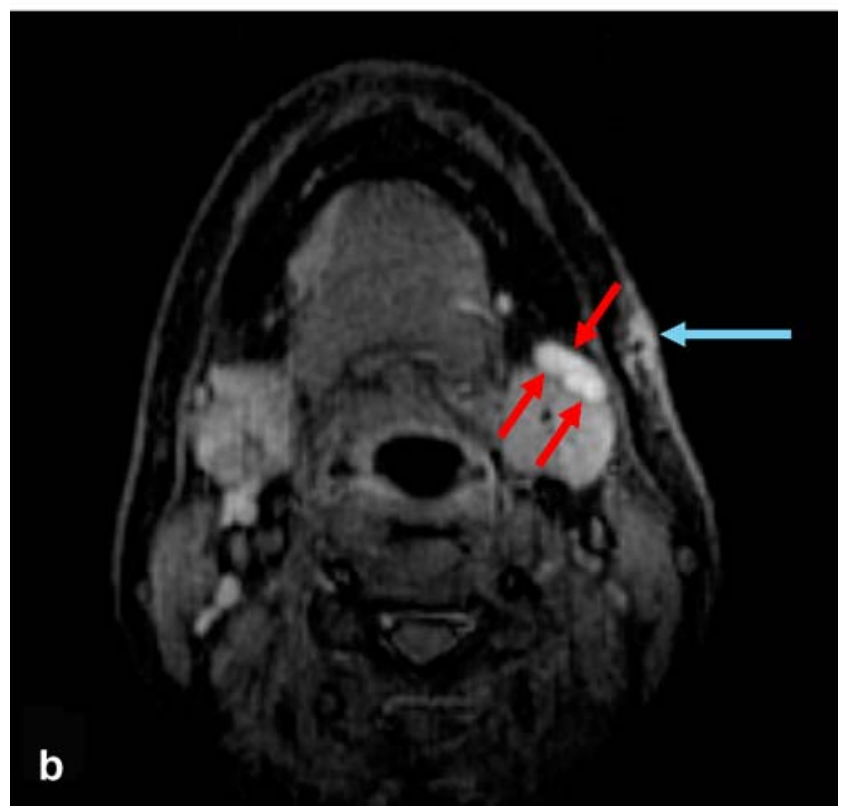

Fig. 2 Lymph node hemorrhage in cases of manual (a, case 3) and ligature strangulation (b, case 4). a This coronal STIR-weighted image (TR 3000, TE 14, TI 150) shows distinct hemorrhage of the subcutaneous fatty tissue on the right side over the mandible (blue arrows). The red arrow points toward a notably hyperintense, hemorrhagic submental lymph node. b Axial STIR-weighted MRI (TR 3000, TE 13, TI 150). A hemorrhagic lymph node (red arrows) and, again, hemorrhage of the subcutaneous fat tissue on the left side (blue arrow) are present. The left lateral submandibular gland also appears slightly hyperintense

reported anxiety but described no signs of cerebral hypoxia. No petechiae. MRI scan $19.5 \mathrm{~h}$ after the incident.

Case 13: Forty-year-old man. Forearm choke hold resulting in dizziness and anxiety. No petechial hemorrhages. Localized pain on pressure on the left side of the neck in the laryngeal region. MRI scan $20.5 \mathrm{~h}$ after the act. 

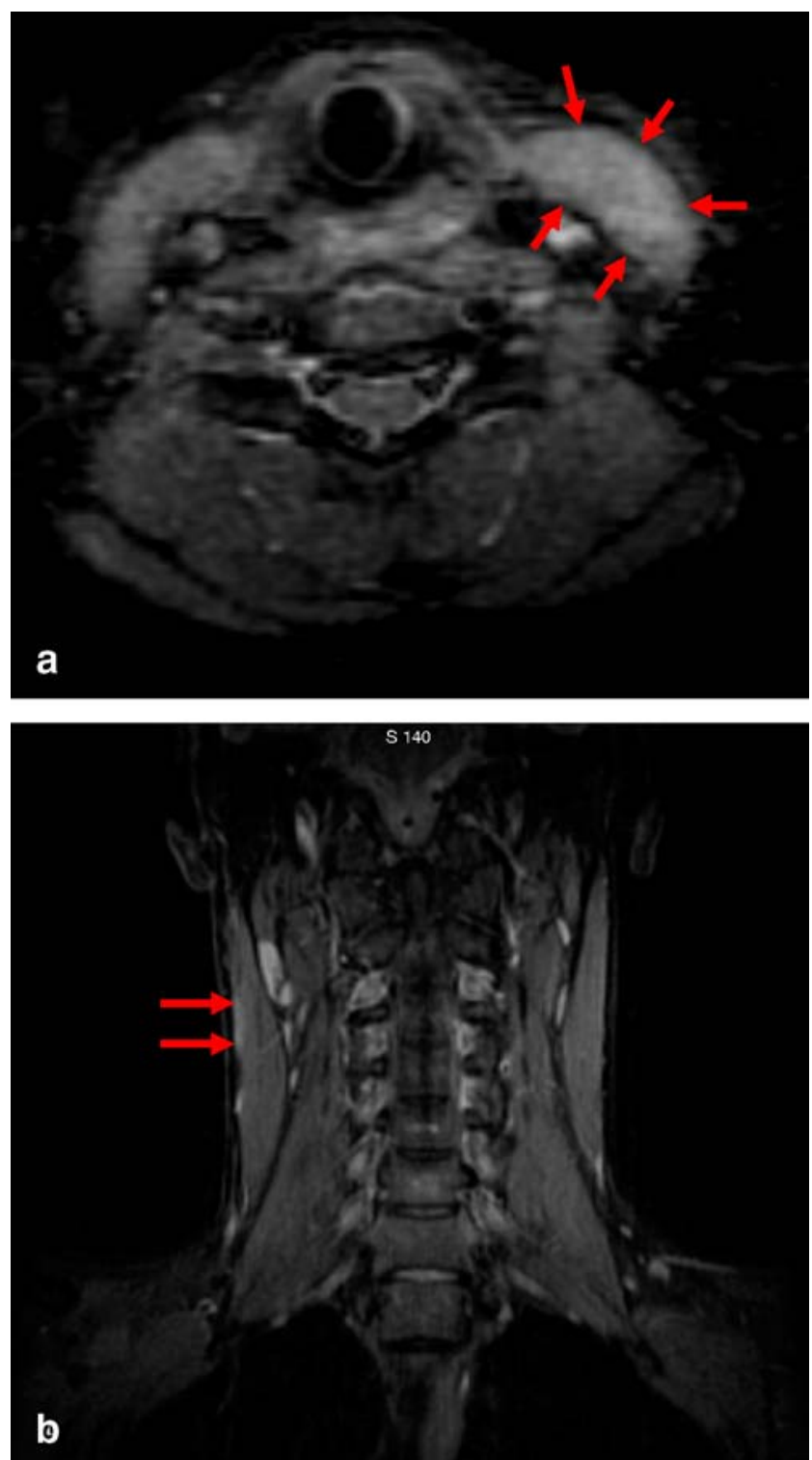

Fig. 3 Muscle findings in ligature strangulation (a, case 8) and a forearm choke hold (b, case 5). a In this axial STIR-weighted MR image (TR 2760, TE 14, TI 150), an asymmetry with swelling and hyperintensity of the left sternocleidomastoid muscle is evident even at 12 days after the incident. The muscle appears tumid and hyperintense, a finding that reflects hemorrhage and swelling (arrows). The radiological finding corresponded to the clinical status of pain on palpation on the left neck side. No externally visible findings were present in this case. b The MR image (coronal STIR, TR 3000, TE 14, TI 150) demonstrates slightly hyperintense regions in the external portions of the right sternocleidomastoid muscle (arrows), which represent superficial muscle hemorrhage

Case 14: Thirty-three-year-old woman. Manual strangulation causing impaired vision (seeing black void). No petechial hemorrhages upon forensic examination. MRI scan $21.5 \mathrm{~h}$ after the incident.
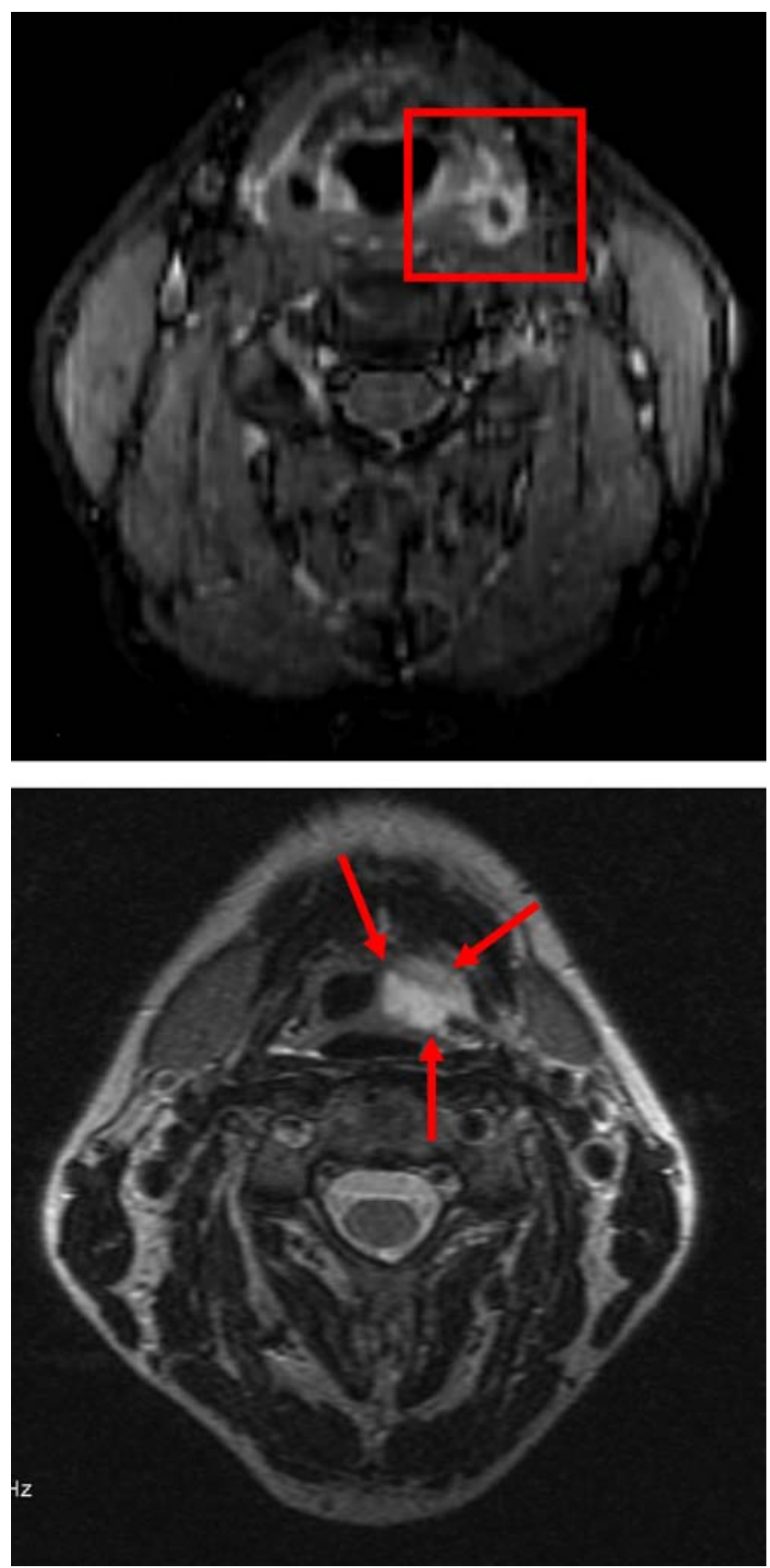

Fig. 4 Inner soft tissue findings in two manual strangulation cases (a, case 2; b, case 9). a The axial STIR MR image (TR 3000, TE 14, TI 150) demonstrates distinct hemorrhage in close proximity to the larynx on the left side after severe strangulation. The patient, who had been manually strangled, reported a "blackout" and dizziness. The case was classified as life-threatening based on the radiological findings (which also included lymph node hemorrhage, soft tissue and muscle hemorrhage) in addition to the classical forensic examination results. b This axial T2-weighted image (TR 4000, TE 105) reveals hematoma in the soft tissues of the hypopharynx and left vallecula. The finding indicates severe strangulation and is in agreement with the statement of the victim of having suffered impairment of vision as a sign of cerebral hypoxia 
Magnetic resonance imaging

The MRI scan was performed approximately 1-2 days after the incident in most cases (median $20.5 \mathrm{~h}$, mean $44.7 \mathrm{~h}$ ). Usually a police officer accompanied the victims to the MR examination. Before starting, the persons had to answer questions concerning their medical history and to give their written consent. In two cases, a low dose of benzodiazepine was given on request of the probands. The same imaging protocols as in routine radiological practice were used.

A neck coil was used for imaging. The MR neck protocol included standard T2-weighted sequences (FSE, TR/TE 4000/90-105 ms), short tau inversion recovery (STIR; TR/TE 3000/14, TI 150), and T1-weighted sequences (SE, TR/TE 400/15-20 ms). The slice thickness was 2-4 mm with gaps of $0.2-1 \mathrm{~mm}$. Total MR neck examination time did not exceed approximately $1 \mathrm{~h}$. The MRI examination was limited to the neck.

MRI data were transferred to a workstation (GE Advantage Windows workstation version 4.1, GE medical systems, Milwaukee, WI), with the post-processing being performed using software provided with the workstation by the manufacturer. MRI examination fees of around 600 Swiss Francs (400 euro) per patient were paid by the local justice departments.

\section{Evaluation of the radiological findings}

Two board-certified radiologists (P.V., A.C.) evaluated the imaging findings in independent, blinded readings. Both

Table 1 Evaluation of the radiological data

\begin{tabular}{|c|c|c|}
\hline Finding & $\begin{array}{l}\text { MR } \\
\text { imaging } \\
\text { criteria }^{\mathrm{a}}\end{array}$ & \\
\hline \multirow[t]{3}{*}{$\begin{array}{l}\text { Hemorrhage: acute } \\
\text { ( } 3 \text { h- } 3 \text { days after } \\
\text { incident })\end{array}$} & General & $\begin{array}{l}\text { Side difference: often } \\
\text { asymmetric swelling if the } \\
\text { injured tissue is covered by } \\
\text { fasciae. Sedimentation effects } \\
\text { possible in case of bleeding } \\
\text { into a cavity. }\end{array}$ \\
\hline & $\mathrm{T} 1$ & Iso-hypointense \\
\hline & $\mathrm{T} 2$ & Iso-hyperintense \\
\hline \multirow{2}{*}{$\begin{array}{l}\text { Hemorrhage: } \\
\text { subacute ( } 3 \text { days- } \\
2 \text { weeks) }\end{array}$} & $\mathrm{T} 1$ & Hyperintense \\
\hline & $\mathrm{T} 2$ & Hyperintense \\
\hline \multirow{2}{*}{$\begin{array}{l}\text { Hemorrhage: chronic } \\
(2+\text { weeks })\end{array}$} & $\mathrm{T} 1$ & Hyper- or hypointense \\
\hline & $\mathrm{T} 2$ & Hyperintense \\
\hline \multirow[t]{3}{*}{ Edema } & General & Swelling and asymmetry \\
\hline & $\mathrm{T} 1$ & Hypointense (dark) \\
\hline & $\mathrm{T} 2$ & Hyperintense \\
\hline
\end{tabular}

${ }^{a}$ The temporal appearance of hemorrhage depends on field strength and MRI technique. had years of experience with the diagnosis of neck and ENT findings. Morphological alterations (e.g., swelling, asymmetry) and alterations of the signal intensity were used as the criteria indicating pathological findings at the radiological evaluation (Table 1) [13]. To be judged as pathological, alterations had to be identified in more than one MR sequence and plane each. In view of the lack of a gold standard for internal strangulation lesions and the juridical consequences of forensic diagnosis, only the findings that were detected by both radiologists were considered positive. For the assessment of their lifethreatening quality, the radiological findings were hypothetically classified according to anatomical and imaging characteristics, and correlated with the information from the classical forensic examination.

\section{Forensic examination}

A board-certified forensic pathologist performed the standard forensic examination a few hours after the incident. There was one exception in which the victim did not report the act for approximately 10 days (case 8). The examination included the evaluation of injuries of the neck and whole body, as well as the evaluation of petechial hemorrhages or other signs of strangulation such as neck pain, hoarseness, or pain while swallowing. Each person was asked if they had lost consciousness during the act or had experienced hallucinatory phenomena. Also, loss of urine or feces was noted.

\section{Results}

The results from the MR examinations are shown in Table 2. Table 3 summarizes the classification of the danger to life using only the classical criteria or the classical criteria in combination with MRI. Of the 14 cases, 10 presented with subcutaneous hemorrhage that was diagnosed without difficulty. Fatty tissue hematoma did not exactly correlate with the externally visible findings of bruises or abrasions in most cases (Fig. 1). The extent of the subcutaneous hemorrhage was underestimated during the external inspection, even when a second look with knowledge of the imaging findings was performed. Occasionally the patients showed no corresponding externally visible injuries, but reported a localized pain in the affected regions. Another regularly detected MRI finding was hemorrhage in the neck and larynx or the masseter muscles (Fig. 3); additionally, the platysma (superficial neck muscle) was affected in five cases. The lymph nodes showed radiological characteristics of hemorrhage according to Table 1 in ten cases (Fig. 2). All persons who were ultimately stated as having been in a lifethreatening situation showed the finding. The specificity of 
Table 2 Radiological evaluation of the neck injuries

\begin{tabular}{|c|c|c|c|c|c|c|c|c|c|c|c|c|c|c|}
\hline $\begin{array}{l}\text { Findings at the radiological } \\
\text { evaluation }\end{array}$ & $\begin{array}{l}\text { Case } \\
1\end{array}$ & $\begin{array}{l}\text { Case } \\
2\end{array}$ & $\begin{array}{l}\text { Case } \\
3\end{array}$ & $\begin{array}{l}\text { Case } \\
4\end{array}$ & $\begin{array}{l}\text { Case } \\
5\end{array}$ & $\begin{array}{l}\text { Case } \\
6\end{array}$ & $\begin{array}{l}\text { Case } \\
7\end{array}$ & $\begin{array}{l}\text { Case } \\
8\end{array}$ & $\begin{array}{l}\text { Case } \\
9\end{array}$ & $\begin{array}{l}\text { Case } \\
10\end{array}$ & $\begin{array}{l}\text { Case } \\
11\end{array}$ & $\begin{array}{l}\text { Case } \\
12\end{array}$ & $\begin{array}{l}\text { Case } \\
13\end{array}$ & $\begin{array}{l}\text { Case } \\
14\end{array}$ \\
\hline $\begin{array}{l}\text { Intracutaneous } \\
\text { hemorrhage }\end{array}$ & & & & & & & & & & + & + & & & \\
\hline Subcutaneous hemorrhage & ++ & ++ & ++ & ++ & ++ & ++ & ++ & & & ++ & & & ++ & + \\
\hline Platysma hemorrhage & & & ++ & & + & & & & ++ & ++ & & & & + \\
\hline Intramuscular hemorrhage & ++ & + & ++ & ++ & ++ & + & & ++ & ++ & ++ & & + & & \\
\hline Lymph node hemorrhage & ++ & ++ & ++ & ++ & ++ & & & ++ & ++ & ++ & + & & ++ & \\
\hline $\begin{array}{l}\text { Hemorrhage of the } \\
\text { salivary glands }\end{array}$ & + & & & + & + & & & & & ++ & & & & \\
\hline $\begin{array}{l}\text { Edema of the laryngeal } \\
\text { region }\end{array}$ & & & & & & & & & & & & & ++ & + \\
\hline $\begin{array}{l}\text { Soft part bleeding in the } \\
\text { pharynx }\end{array}$ & & ++ & & & & & & & ++ & & & & & \\
\hline $\begin{array}{l}\text { Soft part bleeding in the } \\
\text { larynx region }\end{array}$ & & ++ & & & & & & & ++ & & & & + & \\
\hline $\begin{array}{l}\text { Additional findings } \\
\text { (previously present) }\end{array}$ & & & (a) & (b) & & & & & & & & & & \\
\hline
\end{tabular}

Two plus signs $(++)$ indicate findings observed by both radiologists with high degree of confidence. A plus sign $(+)$ indicates findings observed by one or both radiologists as suspected, with low degree of confidence. Status post-cerebellar infarction is indicated by $(a)$, while $(b)$ indicates single hypertrophic lymph node in the mediastinum.

lymph node hemorrhage in severe strangulation was $88 \%$ and the accuracy $93 \%$, respectively.

In one case with hyperintensity in the T2-weighted sequences, there was clinical suspicion of non-traumatic lymph node alterations corresponding to an inflammatory response. This patient showed further signs of an infection with a general increase of T2-hyperintense lymphatic tissue in the pharynx and larynx region.
The hemorrhages in the muscles, lymph nodes, or deep neck structures (Fig. 4) barely correlated with externally visible injuries. Three persons who suffered from localized neck pain in the larynx region (case 2, 9, and 13) revealed hemorrhage of the soft tissues near the larynx or pharynx at MRI, correlating with the clinical finding of painful palpation. In two cases, relevant, preexisting, but formerly unknown findings were detected at MRI. This resulted in

Table 3 Evaluation of the danger to life based on classical forensic criteria and MRI

\begin{tabular}{|c|c|c|c|c|c|c|c|}
\hline \multirow{3}{*}{$\begin{array}{l}\text { Danger to life } \\
\text { Case no. } \\
1\end{array}$} & \multicolumn{3}{|c|}{ Clinical-forensic assessment } & \multicolumn{2}{|c|}{ MRI assessment } & \multicolumn{2}{|c|}{ Interpretation of the danger to life } \\
\hline & Pet & $\mathrm{LC}$ & cHyp & Crit struct & LN Hem & $\sum$ Classical & $\sum$ Classical \& MRI \\
\hline & Yes & Yes & Yes & Yes & Yes & Yes & Yes \\
\hline 2 & & & Yes & Yes & Yes & No & Yes \\
\hline 3 & Yes & Yes & Yes & Yes & Yes & Yes & Yes \\
\hline 4 & Yes & & Yes & Yes & Yes & Yes & Yes \\
\hline 5 & Yes & & Yes & Yes & Yes & Yes & Yes \\
\hline 6 & & & Yes & & & No & No \\
\hline 7 & & & Yes & & & No & No \\
\hline 8 & & N/A & N/A & & Yes & Unclear & Unclear \\
\hline 9 & & & Yes & Yes & Yes & No & Yes \\
\hline 10 & & Yes & Yes & Yes & Yes & No & Yes \\
\hline 11 & & & Yes & & Yes & No & No \\
\hline 12 & & & & & & No & No \\
\hline 13 & & & Yes & Yes & Yes & No & Yes \\
\hline 14 & & & Yes & & & No & No \\
\hline
\end{tabular}

Pet petechial bleedings, LC loss of consciousness, cHyp other signs of cerebral hypoxia [dizziness, blackout, impaired vision ("seeing black void"), hallucinatory phenomena, loss of urine], $\sum$ classical danger to life according to the classical clinical-forensic examination results,

Crit struct hemorrhage near the "critical neck structures" (see text), LN Hem lymph node hemorrhage, $\sum$ classical \& MRI danger to life using the MRI examination results in addition to the case data, $N / A$ no data available 
further medical examination or treatment: one woman showed extensive infarction of both cerebellar hemispheres, which was not associated with clinical symptoms, and the etiology of this finding remained unclear. In another woman enlargement and alteration of one mediastinal lymph node was detected, which led to a follow-up examination.

\section{Discussion}

Clinical forensic medicine, i.e., forensic examination of the living, is of increasing relevance in the field of forensic sciences. The growing sensitivity of the public concerning domestic violence and sexual assault and an increasing number of cases reported to the police or the district attorney have caused an increase in the number of clinical cases subjected to forensic institutes.

In clinical medicine, CT and MR imaging of the neck are commonly used when assessing laryngeal injuries due to blunt or penetrating trauma or tumors [14]. However, only few reports deal with neck alterations after survived strangulation [15-17], and the radiological evaluation is mainly based on CT. According to the literature, MRI has not been used for the assessment of survived strangulation in forensic cases apart from one manual strangulation incident that was reported by Yen et al. [12]. In our actual study, the strangulation victims underwent MRI but did not undergo CT of the neck. The decision to perform MRI only was based on the fact that MRI is the method of choice when it comes to evaluate soft tissue lesions. Since there was a forensic but no clinical indication, CT scans entailing radiation exposure of the patient were not performed. However, should there have been suspicion of laryngeal or hyoid fracture with a need for treatment, CT would have been considered.

According to the results of this study and despite the limited experience with the use of MRI in survived strangulation cases, MRI seems to be suited to objectively document internal injuries of the neck that cannot be detected using classical examination methods. MRI demonstrated subcutaneous hemorrhage even when there was no corresponding externally visible bruise or abrasion. The extent of subcutaneous hemorrhage was generally underestimated based on the external forensic examination. Muscle hemorrhage was another frequent finding in MRI, and lymph nodes or, less often, the salivary glands showed radiological signs of hemorrhage. Other findings escaping detection during the classical external examination comprised hemorrhages in the pharyngeal and laryngeal soft tissues, which were found in three persons who all had localized neck pain on palpation upon external examination. According to the experience of this study, the traumatic inner findings remain visible by MRI for at least 3 days after the incident; in one case, distinct hemorrhage of the left sternocleidomastoid muscle and submandibular lymph nodes was seen even 12 days after the act. Although there is clinical evidence that processes in the living such as swelling and edema might lead to an alteration of the MRI signal, the number of our cases is too small to allow an interpretation concerning time-dependent behavior of the internal neck injuries.

A disadvantage in examining strangulation survivors was that, especially in cases of severe strangulation, the patients reported anxiety caused by the relatively small diameter of the MRI gantry and the necessity to put a neck coil closely around the throat. Low-dosed benzodiazepines were given to two persons on their request. In two other cases, a medical staff member or a victim's companion remained present throughout the MRI scans, which is not usual in routine clinical practice. The anxiety caused motion, and the motion artifacts that resulted from the psychological stress lowered the quality of the radiological data in two cases. Besides motion artifacts caused by victim's movements, artifacts due to blood circulation and breathing were observed in all cases; however, the broad clinical-radiological experience helped to distinguish artifact from pathological findings.

\section{Assessment of life-threatening injuries}

In clinical forensic medicine, the evaluation of the severity of a strangulation incident is not primarily intended to judge the injuries in view of the necessity for medical treatment, but aims to discover evidence that the victim had been in a dangerous, life-threatening situation due to cerebral hypoxia. While petechial bleeding is a well-established finding of life-threatening strangulation [18], it is not found in some patients even after severe compression of the neck. An independent additional parameter indicating life-threatening injury would therefore be useful. We think that the criteria mentioned below might fulfill this role. There is no gold standard for this kind of examination in the living; however, the fact that all our cases presenting with petechial hemorrhage also showed radiological signs of severe strangulation (Table 3) might indicate the potential of MRI to become a gold standard in the future.

The following considerations about the interpretation of MRI-documented internal neck injuries regarding the severity of an act shall provide a basis for discussion. There is a fundamental need for the forensic community to discuss the possible interpretation of internal strangulation findings and to develop standards for their evaluation and forensic interpretation. Clinical radiologists should also be made aware of the forensic relevance of certain radiological signs. All findings will need to be confirmed in the course of further prospective studies on larger cohorts. 
The assessment of the danger to life was performed using MRI in addition to the classical examination results (Table 3). For the forensic classification of the incidents that were examined in this study, we used the following principles:

- The carotid arteries and the upper airways were defined as the main "critical neck structures" where vigorous compression lasting at least a few seconds is expected to result in cerebral hypoxia. According to our experience from autopsy, distinct hemorrhage in close proximity to the critical neck structures is proof of vigorous compression and, therefore, indicates a high probability of cerebral hypoxia and a life-threatening situation for the victim during the act. However, in contrast to petechial bleedings, these internal hemorrhages indicate the intensity of an assault but currently provide no information about the duration of neck compression.

- Hemorrhage of the lymph nodes shows an excellent concordance with the severity of strangulation (Table 3). Although histopathological examinations of the lymph nodes could not be obtained in our cases for obvious reasons, the radiologically visible alterations corresponded well to the findings we observed in the previous postmortem study [12]. In the deceased, a histopathological examination shows massive hemorrhage of the affected lymph nodes that are characterized by the same radiological signs we observe in the living. Since hemorrhagic lymph nodes were regularly found without corresponding hemorrhage of the overlying soft tissues in the surviving victims, they might possibly represent an early sign of "inner congestion." When we consider the regularity with which the finding has been observed even when petechial bleedings were absent, lymph node bleedings might even appear before the occurrence of externally visible petechiae. However, since MRI cannot differentiate between hemorrhage due to congestion and hemorrhage after direct lymph node trauma, a direct traumatic genesis must also be considered. Further studies focusing on the morphology and traumatology of the lymph nodes will help to clarify their role in the pathophysiology of strangulation.

- Further clinical evidence of severe strangulation such as petechial bleedings or signs of impaired cerebral function confirms the life-threatening quality and is therefore needed to support the radiology-based interpretation.

- The radiological results are used in addition to the classical forensic examination and the police reports.

- For the forensic interpretation of neck MRI findings, it is important to exclude or be aware of other injuries such as blunt trauma due to falls from a height or beatings, as these might also result in injuries of the neck structures.
In 10 of the 14 cases $(71 \%)$, the interpretation of the lifethreatening quality of the event was concordant between the sole classical and the classical with additional MRI examination. Four of these were determined to having caused endangerment to life, five were not life-threatening acts, and one remained unclear. In four cases $(29 \%)$, the incident was interpreted as life-threatening based on the classical examination in conjunction with MRI; the classical examination only had not determined mortal danger. There was no case in which the classical examination without MRI revealed a life-threatening act and the examination with MRI gave no clues for this.

Recapitulating the study results, we assume that MRI has a great potential as an added value to classical forensic examination by offering visualization of internal neck findings in survived strangulation cases. This is also reflected in the reaction of the local judicial and police departments who request MRI in each case of strangulation submitted to the forensic institute. Future studies and growing experience, as well as an appropriate discussion in the forensic expert boards will help clarify the role of internal injuries in view of the interpretation of the lifethreatening quality of an incident.

\section{References}

1. Brinkmann B, Püschel K (eds) (1990) Ersticken-Fortschritte in der Beweisführung. Springer, Berlin Heidelberg New York

2. Härm T, Rajs J (1981) Types of injuries and interrelated conditions of victims and assailants in attempted and homicidal strangulation. Forensic Sci Int 18(2):101-123

3. Brinkmann B (2004) Ersticken. In: Brinkmann B, Madea B (eds) Handbuch Gerichtliche Medizin. Springer, Berlin Heidelberg New York, pp 761-794

4. Mueller B (1975) Erstickung. In: Mueller B (ed) Gerichtliche Medizin. Springer, Berlin Heidelberg New York, pp 439-464

5. Di Maio DJ, Di Maio VJM (1989) Strangulation. In: Di Maio DJ, Di Maio VJM (eds) Forensic pathology, 1st edn. CRC Press, New York, pp 222-244

6. Meier C (2005) Die Lebensgefährdung. Ph.D. Thesis, University of Freiburg, Switzerland

7. Jackowski C, Thali M, Aghayev E, Yen K, Sonnenschein M, Zwygart K, Dirnhofer R, Vock P (2005) Postmortem imaging of blood and its characteristics using MSCT and MRI. Int J Legal Med 19:1-8

8. Jackowski C, Aghayev E, Sonnenschein M, Dirnhofer R, Thali MJ (2006) Maximum intensity projection of cranial computed tomography data for dental identification. Int J Legal Med 120 (3):165-167

9. Yen K, Sonnenschein M, Thali MJ, Ozdoba C, Weis J, Zwygart K, Aghayev E, Jackowski C, Dirnhofer R (2005) Postmortem multislice computed tomography and magnetic resonance imaging of odontoid fractures, atlantoaxial distractions and ascending medullary edema. Int J Legal Med 119(3):129-136

10. Hayakawa M, Yamamoto S, Motani H, Yajima D, Sato Y, Iwase H (2006) Does imaging technology overcome problems of conventional postmortem examination? A trial of computed tomography 
imaging for postmortem examination. Int J Legal Med 120(1):2426

11. Schulz R, Muhler M, Mutze S, Schmidt S, Reisinger W, Schmeling A (2005) Studies on the time frame for ossification of the medial epiphysis of the clavicle as revealed by CT scans. Int J Legal Med 119(3):142-145

12. Yen K, Thali MJ, Aghayev E, Jackowski C, Schweitzer W, Boesch C, Vock P, Dirnhofer R, Sonnenschein M (2005) Strangulation signs: initial correlation of MRI, MSCT, and forensic neck findings. J Magn Reson Imaging 22(4):501-510

13. Bradley WG (1999) Hemorrhage. In: Stark DD, Bradley WG (eds) Magnetic resonance imaging. Mosby, St. Louis, pp 13291359
14. Castelijns JA, van den Brekel MW, Niekoop VA, Snow GB (1996) Imaging of the larynx. Neuroimaging Clin N Am 6 (2):401-415

15. Lupetin AR, Hollander M, Rao VM (1998) CT evaluation of laryngotracheal trauma. Semin Musculoskelet Radiol 2(1):105-116

16. Borowski DW, Mehrotra P, Tennant D, El Badawey MR, Cameron DS (2004) Unusual presentation of blunt laryngeal injury with cricotracheal disruption by attempted hanging: a case report. Am J Otolaryngol 25(3):195-198

17. Stanley RB Jr, Hanson DG (1983) Manual strangulation injuries of the larynx. Arch Otolaryngol 109(5):344-347

18. Plattner T, Bolliger S, Zollinger U (2005) Forensic assessment of survived strangulation. Forensic Sci Int 153(2-3):202-207 